BOOK REVIEW

\section{Girl Trouble: Panic and Progress in the History of Young Women}

Carol Dyhouse. London, UK: Zed Books, 2013. ISBN-13: 978-1-780-32493-7. Price: f14.99. Pages: 352 (paperback)

Are girls better off today than they were at the beginning of the 20th century? This question is central to this engaging book, which traces the social history of the changes to girls' lives in Britain from the 1880 s to the present day.

The debate as to whether girls are victims or beneficiaries of social change has raged throughout modern history. Beginning with the growth of feminine self-awareness and improvements in education before the First World War, the book alerts readers to the anxiety about social disorder resulting from girls' behaviour and political consciousness, which ultimately caused a moral panic with girls being sent to 'approved schools' in an attempt to control their behaviour. The Second World War proved a major catalyst for social change but caused new moral concern over 'good time girls' fuelled by consumerism, films and popular music, risking their virtue for nylons brought over by
American servicemen. In fact, it seems as if public outrage at girls' perceived misbehaviour can be seen throughout the generations with reference to 'brazen flappers', teddy girls, beat girls, dolly birds and ladettes!

For those working in sexual and reproductive health, almost every page of this book highlights relevant issues including sobering accounts of the struggle for safe abortion, contraception and treatment of sexually transmitted infections. It will come as no surprise that one of the main concerns throughout the book is fear of unintended pregnancy and the challenge for women to control their fertility. Unmarried motherhood brought shame on the 'good name of a family', leading to girls being forced to make their way on the streets in the early 20th century; and although societal attitudes may have mellowed with regard to single parenting, the book highlights underlying moral concerns regarding teenage pregnancy and contraception that are still debated today. Sex education is one example that still continues to engender discussion between governments, schools and parents, with no real consensus of standardised curriculum or provision for children and young people.

Girl Trouble details a rich account of changes in the lives of young women during the last century, most of which are directly related to issues of sexual and reproductive health. Carol Dyhouse is a social historian and research professor of history who has spent her academic career studying young women, education and popular culture, and the text is reliably supported by detailed notes, references and government legislation with sources from books, newspapers, medical texts, feminist writing, government reports and photographs. The book is both a good read and an excellent resource for those interested in sexual health.

Are girls better off today than they were at the beginning of the 20th century? Dyhouse suggests the answer is yes, but as inequalities and double standards still abound there is no room for complacency.

Reviewed by Jill Shawe

Reader in Midwifery Practice and Director of the Centre for Research in Nursing and Midwifery Education, University of Surrey, Guildford, UK; j.shawe@surrey.ac.uk

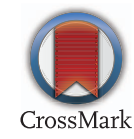

J Fam Plann Reprod Health Care 2014;40:231. doi:10.1136/jprhc-2014-100964 